\title{
Estimates of eddy turbulence consistent with seasonal variations of atomic oxygen and its possible role in the seasonal cycle of mesopause temperature
}

\author{
M. N. Vlasov and M. C. Kelley \\ School of Electrical and Computer Engineering, Cornell University, Ithaca, NY, USA \\ Received: 5 April 2010 - Revised: 18 October 2010 - Accepted: 19 October 2010 - Published: 18 November 2010
}

\begin{abstract}
According to current understanding, adiabatic cooling and heating induced by the meridional circulation driven by gravity waves is the major process for the cold summer and warm winter polar upper mesosphere. However, our calculations show that the upward/downward motion needed for adiabatic cooling/heating of the summer/winter polar mesopause simultaneously induces a seasonal variation in both the $\mathrm{O}$ maximum density and the altitude of the [O] peak that is opposite to the observed variables generalized by the MSISE-90 model. It is usually accepted that eddy turbulence can produce the $[\mathrm{O}]$ seasonal variations. Using this approach, we can infer the eddy diffusion coefficient for the different seasons. Taking these results and experimental data on the eddy diffusion coefficient, we consider in detail and estimate the heating and cooling caused by eddy turbulence in the summer and winter polar upper mesosphere. The seasonal variations of these processes are similar to the seasonal variations of the temperature and mesopause. These results lead to the conclusion that heating/cooling by eddy turbulence is an important component in the energy budget and that adiabatic cooling/heating induced by upward/downward motion cannot dominate in the mesopause region. Our study shows that the impact of the dynamic process, induced by gravity waves, on $[\mathrm{O}]$ distributions must be included in models of thermal balance in the upper mesosphere and lower thermosphere (MLT) for a consistent description because (a) the $[\mathrm{O}]$ distribution is very sensitive to dynamic processes, and (b) atomic oxygen plays a very important role in chemical heating and infrared cooling in the MLT. To our knowledge, this is the first attempt to consider this aspect of the problem.
\end{abstract}

Keywords. Meteorology and atmospheric dynamics (General circulation; Middle atmosphere dynamics; Turbulence)

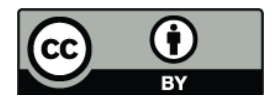

Correspondence to: M. C. Kelley (mck13@cornell.edu)

\section{Introduction and background}

The thermal balance of the mesosphere and lower thermosphere (MLT) is controlled by radiative heating due to absorption of solar UV radiation by $\mathrm{O}_{2}$ and $\mathrm{O}_{3}$, by chemical heating from exothermic reactions, by radiative cooling associated with infrared emission of $\mathrm{CO}_{2}$, and heating and cooling induced by dynamic processes. The latter includes compression/expansion caused by downward/upward motion associated with the gravity wave-driven meridional circulation, as well as direct heating due to the gravity wave dissipation and turbulent diffusion from breaking gravity waves and/or the Kelvin-Helmholtz instability (KHI), caused by sheared flow.

The various contributions of different dynamic processes to the energy budget of MLT are still in much debate (Dunkerton, 1978; Hines, 1997; Medvedev and Klaassen, 2003; Becker, 2004; Akmaev, 2007; Becker and McLandress, 2009). According to an overview of chemical and physical processes presented by Smith (2004), adiabatic heating/cooling caused by sinking/upwelling is the most important process and provides the unusual temperature structure of a warm winter/cold summer in the upper mesosphere. According to the SOCRATES model used by Smith, the maximum adiabatic heating is found to be $16 \mathrm{~K} /$ day in the winter polar mesosphere and the maximum adiabatic cooling rate is found to be $-14 \mathrm{~K} /$ day during the summer polar mesopause. This cooling/heating is caused by mean vertical motions with a magnitude of $\pm 2 \mathrm{~cm} / \mathrm{s}$. In this model, eddy diffusive heating is absent in the summer mesopause. According to the SOCRATES model, the cold summer mesopause is caused entirely by adiabatic cooling, with maximum upward motion (expansion) occurring at the altitude of the mesopause. During the winter mesopause, adiabatic heating only takes place below the mesopause since the maximum of the downward motion (compression) occurs below the mesopause. In this case, chemical heating is

Published by Copernicus Publications on behalf of the European Geosciences Union. 


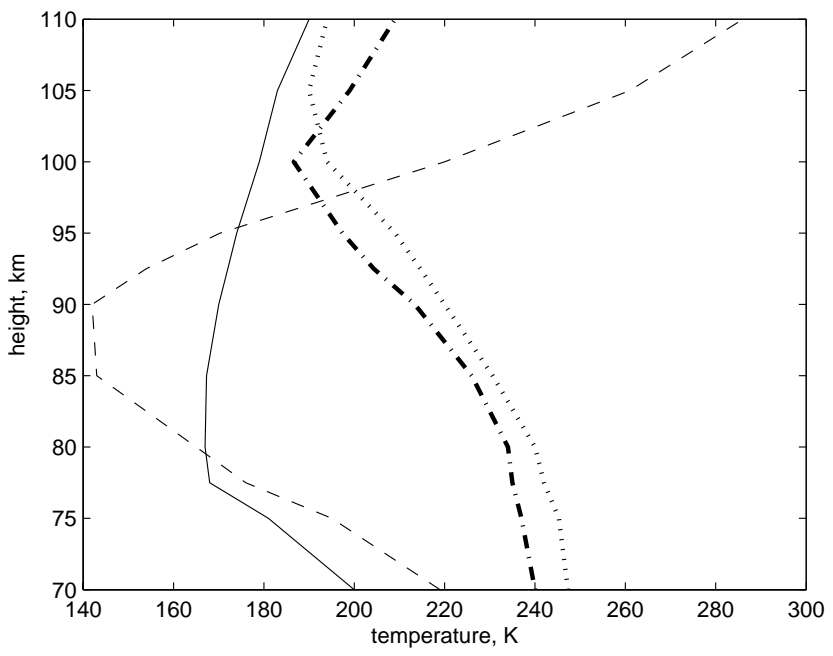

Fig. 1. Temperature height profiles calculated by the MSISE-90 model $\left(14: 00 \mathrm{LT}, 21\right.$ December 2000 , Long. $\left.=285^{\circ} \mathrm{E}\right)$ at $70^{\circ} \mathrm{S}$ latitude in the summer cold mesosphere (dashed line) and at $70^{\circ} \mathrm{N}$ latitude in the winter warm mesosphere (dashed-dotted line), and as calculated by the SOCRATES model at the same latitudes in summer (solid line) and in winter (dotted line).

important (Berger and von Zahn, 1999). As seen from Fig. 1, agreement exists between the height profiles of the temperature calculated by the model and given by the MSISE90 model (Hedin, 1991) at altitudes below the polar winter mesopause, but the model and the MSISE-90 data are very different above the mesopause. The agreement between the SOCRATES and MSISE-90 models is much worse around the polar summer mesopause. The strong discrepancies between the SOCRATES models and the empirical model MSISE-90 are as follows:

1. The SOCRATES model cannot reproduce one of the main features of the mesosphere-lower thermosphere (MLT): the decrease in the lower boundary of the thermosphere from winter to summer. It is very difficult to believe that the lower boundary of the thermosphere is located below $80 \mathrm{~km}$ in summer, as seen in Fig. 1 .

2. In Fig. 2, a strong discrepancy exists between the calculated temperatures and the temperatures given by the MSISE-90 model at middle latitudes.

3. According to the MSISE-90 model, the latitudinal variation of temperature at the winter mesopause does not exceed $8 \mathrm{~K}$, but this variation is $38 \mathrm{~K}$ in the summer mesopause. Also, the MSISE-90 model (see Fig. 3) shows that the maximum decrease in temperature at the summer polar mesosphere from winter solstice to equinox is about $50 \mathrm{~K}$ but the maximum increase in temperature in the winter mesosphere is $20 \mathrm{~K}$ (also see Fig. 3). A mechanism based on adiabatic heat-

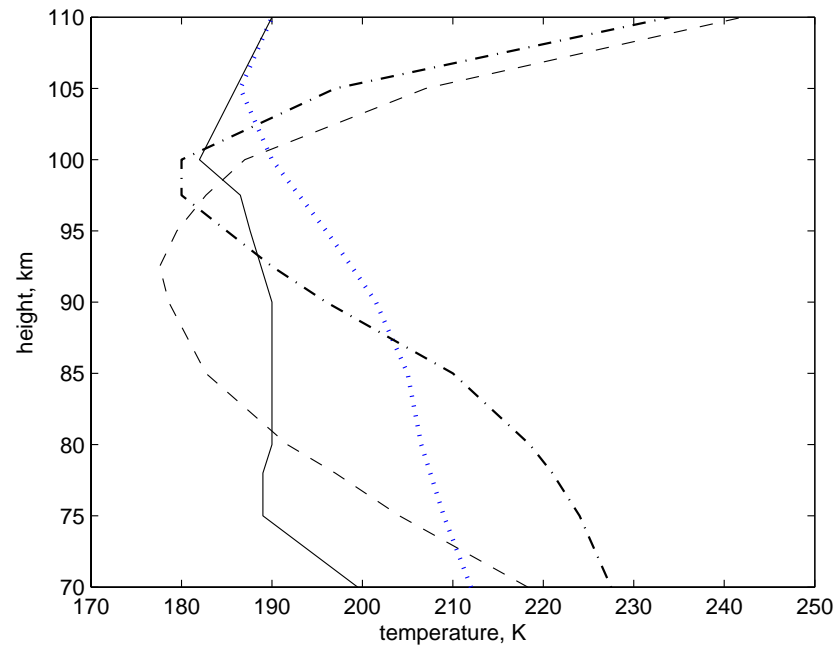

Fig. 2. The same as in Fig. 1 but at latitudes $40^{\circ} \mathrm{N}$ and $40^{\circ} \mathrm{S}$.

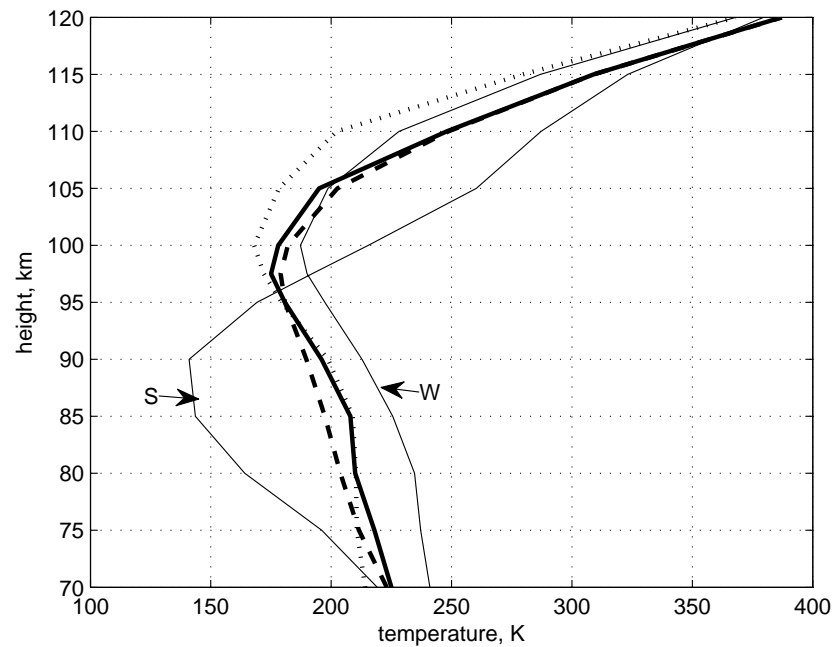

Fig. 3. Temperature height profiles given by the MSISE-90 model at latitudes $70^{\circ} \mathrm{S}$ and $70^{\circ} \mathrm{N}$ (curves labeled $\mathrm{S}$ and $\mathrm{W}$, respectively), at the equator (dotted curve), at winter solstice (14:00 LT, 21 December 2000 , Long. $=285^{\circ} \mathrm{E}$ ), and at latitudes $70^{\circ} \mathrm{S}$ and $70^{\circ} \mathrm{N}$ (dashed and solid curves, respectively) at equinox.

ing/cooling cannot explain these asymmetries between the summer and winter mesosphere.

We note also that the SOCRATES results strongly contradict the heating rate of +10 to $+20 \mathrm{~K} /$ day determined by (a) in situ measurements of neutral density fluctuations in the summer polar mesopause (Lübken, 1997), and (b) the dynamic cooling rate of $-31 \mathrm{~K} /$ day associated with the vertical heat transport by dissipating gravity waves in the mesopause region as measured by a Na lidar at the Starfire Optical Range in winter at middle latitudes (Gardner and Yang, 1998).

Fritts and Luo (1995) presented a model for dynamic forcing of the summer polar mesopause circulation and thermal 
structure at high latitudes. Dynamic forcing is provided by gravity wave energy and momentum fluxes and their divergences. The model gives a turbulent heating rate of +20 to $+25 \mathrm{~K} /$ day in the summer polar mesopause that increases with increasing altitude, reaching $60 \mathrm{~K} / \mathrm{day}$ at $100 \mathrm{~km}$. This high heating requires an upward velocity of $5 \mathrm{~cm} / \mathrm{s}$ to provide net adiabatic cooling in the summer mesopause.

The Fritts and Luo (1995) model shows that eddy turbulence and vertical motion induced by gravity waves play a very important role in the thermal balance in the upper mesosphere. Gardner and Yang (1998) also showed the importance of gravity wave dissipation in thermal balance in the upper mesosphere.

However, Smith (2004), Hocking (1999), and other authors (for example, Brasseur and Solomon, 1986; Brasseur et al., 2000) argue that the impact of gravity waves is restricted to their induced change in the zonal and meridional wind and, correspondingly, to adiabatic heating/cooling induced by the downward/upward motion and that this is the main source of the temperature seasonal variations in the upper mesosphere. Hocking (1999) and Smith (2004) do emphasize many uncertainties in the relationship of turbulent energy dissipation, turbulent heat transport, and diffusion. Hocking notes two main problems: "first, turbulence is very intermittent both temporally and spatially, and very often occurs in thin layers in the middle atmosphere. These thin layers are often separated by regions that are either only weakly turbulent or even laminar. Secondly, the processes which induce diffusion can themselves be scale dependent." These problems are very important when describing short-time variations in the temperature. However, when we try to model such long-time seasonal variations, we need mean values for the statistically steady turbulent motion. Numerous experimental data on eddy turbulence exist (see, for example, Fukao et al., 1994; Lübken, 1997; Hill et al., 1999), and these data facilitate inferring the mean values of eddy turbulence and their longtime seasonal variations. It is important to emphasize that the meridional wind and wind shears are very intermittent in altitude, as can be seen from the measurements (Larsen, 2002), meaning that vertical motion driven by the meridional wind is very intermittent as well. Finally, no available measurements of the vertical velocity exist, and estimates of this velocity from divergence of the horizontal wind are very difficult. However, there are many measurements of the eddy diffusion coefficient.

Several approaches to estimating the heating rates corresponding to turbulent dissipation of gravity wave kinetic energy were developed recently (Medvedev and Klaassen, 2003; Becker, 2004; Akmaev, 2007; Becker and McLandress, 2009). The heating rates estimated by Becker (2004) for summer conditions are similar to the heating rates measured by Lübken (1997), but Becker's peak value is less by a factor of about 2 and the peak height is smaller by $7 \mathrm{~km}$ than Lübken's measured parameters. However, the estimated heating rates for winter conditions are very different from the measured values. There are similar differences between the eddy diffusion coefficients calculated by Becker (2004) and measured by Lübken (1997). Akmaev (2001) simulated an eddy diffusion coefficient peak altitude of $110 \mathrm{~km}$ for January that is higher by $17 \mathrm{~km}$ than the peak altitude measured by Lübken (1997).

To our knowledge, the models explaining the cold summer and warm winter mesopause do not consider the effect of dynamic processes on the distribution of atomic oxygen, which plays an important role in chemical heating and infrared cooling in the upper mesosphere. For example, the extended version of the Canadian Middle Atmosphere Model presented by Fomichev et al. (2002) includes eddy and molecular diffusion and vertical advection, which strongly influence the $[\mathrm{O}]$ distribution. However, the model uses vertical profiles for [O] given by the MSISE-90 model. The infrared radiation of the $15-\mu \mathrm{m} \mathrm{CO} \mathrm{CO}_{2}$ band is the main cooling process in the upper mesosphere. The quenching of excited $\mathrm{CO}_{2}$ by atomic oxygen is one of the most important factors determining this cooling. The authors tried to reduce the cooling rate error below 5\% in the upper mesosphere. However, the variations in atomic oxygen, induced by the dynamic processes included in the model, can change this cooling rate by a few times. Note that atomic oxygen is the main constituent in the thermosphere and that the $\mathrm{O}$ thermospheric density strongly depends on the altitude of the peak density in the upper mesosphere. The altitude of the peak density is controlled by the dynamic processes responsible for the temperature anomaly in the mesopause.

The goal of this paper is to consider the contradiction between the observed seasonal variations of atomic oxygen density distributions in the upper mesosphere and lower thermosphere (MLT) and the impact of upward/downward motion, responsible for the cold summer and warm winter mesopause, on the [O] distribution. We estimate the impact of eddy turbulence and vertical motion on the [O] distributions, derive the eddy diffusion coefficient corresponding to the seasonal variations of $[\mathrm{O}]$ corresponding to the experimental data associated with the MSISE-90 model (Hedin, 1991), and then, using these results, estimate the contribution of heating/cooling of eddy turbulence in the thermal balance of the upper mesosphere and the seasonal variations of mesopause temperature. To our knowledge, this is the first attempt to include a minor constituent in testing theories for the cold summer and warm winter mesopause.

\section{Impact of eddy diffusion and vertical motion on the [O] distribution}

The impact of eddy turbulence on the height distribution of minor constituents is well known (Banks and Kockarts, 1973; Brasseur and Solomon, 1986). Using numerical modeling, Vlasov and Davydov $(1982,1983,1993)$ studied the impact of eddy diffusion, together with vertical motion and 


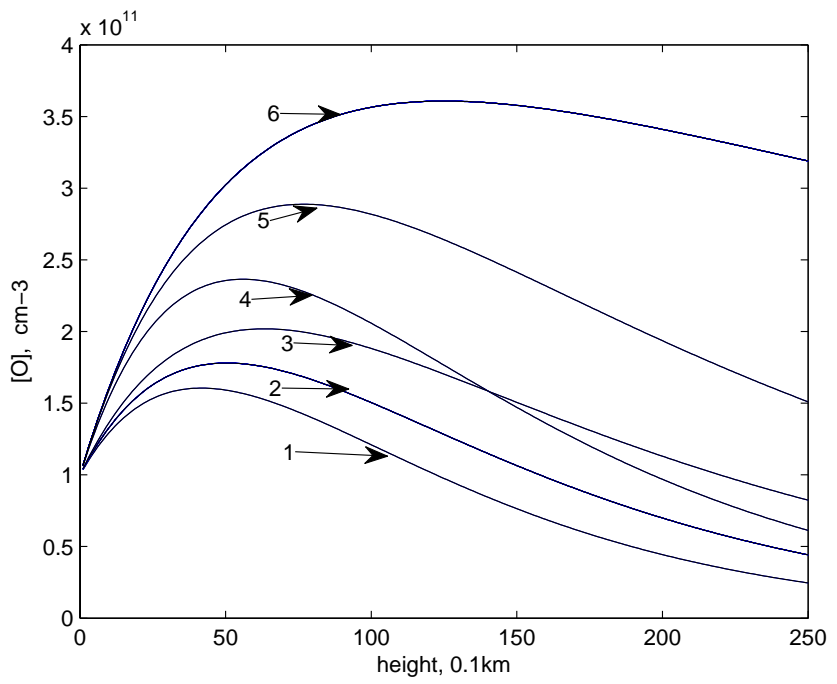

Fig. 4. [O] height profiles calculated by the analytical solution of Eq. (8) above $90 \mathrm{~km}$ for $K_{\text {ed }}^{m}=3 \times 10^{6} \mathrm{~cm}^{2} / \mathrm{s}$ and vertical velocities $V=2,3,4 \mathrm{~cm} / \mathrm{s}$ (curves 1,2 , and 3, respectively), and for $K_{\mathrm{ed}}^{m}=$ $2 \times 10^{6} \mathrm{~cm}^{2} / \mathrm{s}$ and $V=2,3,4 \mathrm{~cm} / \mathrm{s}$ (curves 4,5 , and 6 , respectively).

photochemistry, on the $[\mathrm{O}]$ distribution in the MLT. According to their results, the $\mathrm{O}$ peak density decreases with a $K_{\text {ed }}$ increase. This density decreases even more if a downward motion occurs with eddy turbulence. Also, the altitude of the [O] peak decreases with a $K_{\text {ed }}$ increase, whereas this altitude increases/decreases due to any upward/downward motion. The seasonal variations of the $\mathrm{O}$ peak density and the altitude of the $[\mathrm{O}]$ peak are characterized by an increase in both the $\mathrm{O}$ peak density and the altitude of the $[\mathrm{O}]$ peak from summer to winter by a factor of nearly 2.25 and by $4 \mathrm{~km}$, respectively.

The height distribution of the $\mathrm{O}$ density can be determined using the continuity equation,

$$
\begin{aligned}
& \frac{\partial n}{\partial z}\left[-K_{\text {ed }}(z)\left(\frac{\partial n}{\partial z}+\frac{n}{H}\right)-D\left(\frac{\partial n}{\partial z}+\frac{n}{H_{\mathrm{O}}}\right)+V(z) n\right] \\
& \quad=q(z)-\beta(z) n^{2}
\end{aligned}
$$

where $D$ is the molecular diffusion coefficient, $V$ is the velocity, $q$ is the production rate, $\beta$ is the recombination coefficient, and $H_{\mathrm{O}}$ is the height scale of atomic oxygen.

The solution of this equation, with constant values of $V$, $K_{\text {ed }} \gg D, q=q_{0} \exp (-z / H)$, and $\beta=\beta_{0}=$ constant in the final term $\beta_{0} n$, is given by the formula

$$
\begin{aligned}
n= & n_{0}-\left(\frac{q_{0} H}{\beta_{0} H-V}\right) \exp \left\{\left[-0.5\left(\frac{1}{H}-\frac{V}{K_{\text {ed }}}\right)\right.\right. \\
& \left.\left.-\left[0.25\left(\frac{1}{H}-\frac{V}{K_{\text {ed }}}\right)^{2}+\beta_{0} / K_{\text {ed }}\right]^{0.5}\right]^{z}\right\} \\
& +\frac{q_{0} H}{\beta_{0} H-V} \exp (-z / H)
\end{aligned}
$$

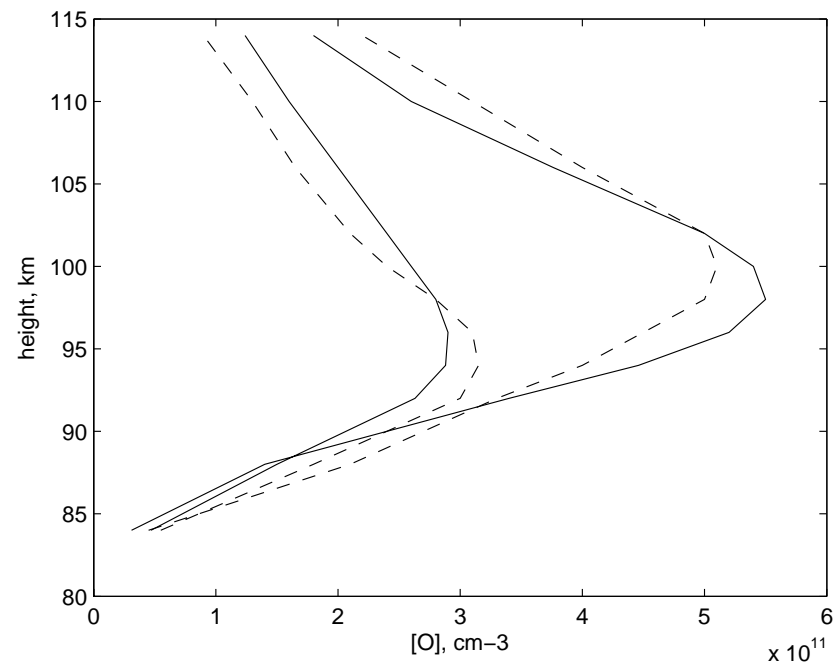

Fig. 5. The calculated [O] height distributions (dashed lines) given by the MSISE-90 model (solid lines) for summer (low densities) and winter (high densities) at latitudes $60^{\circ} \mathrm{N}$ and $60^{\circ} \mathrm{S}$ on $21 \mathrm{De}-$ cember 2000 .

This simple approximation describes the main features that impact the $[\mathrm{O}]$ height distribution: production, loss, and dynamic processes (eddy turbulence and upward motion). As seen from Fig. 4, an increase in the upward velocity induces an increase in the $\mathrm{O}$ density and in the altitude of the [O] peak. A $K_{\text {ed }}$ increase induces an [O] decrease. The effect of these dynamic processes on the [O] distribution is much stronger than a recombination. But, in general, the results of the numerical solution of Eq. (2) with squared-law recombination and an altitude-dependent coefficient show the same impact of eddy diffusion and vertical motion in the [O] distribution (Vlasov and Davydov, 1982, 1993). In any case, the upward/downward motion in the polar summer/winter mesosphere induces a seasonal variation in the $\mathrm{O}$ density and in the altitude of the $[\mathrm{O}]$ peak, contrary to the experimental data. Finally, we note that there is no experimental evidence for upward/downward motion in the mesosphere, but there is a set of experimental data on eddy turbulence. Using the numerical model developed by Vlasov and Davydov $(1983,1993)$ with eddy diffusion coefficients approximated by the formulas close to the coefficients obtained by Lübken (1997), it is possible to reproduce the [O] seasonal variations given by the MSISE-90 model, as seen from Fig. 5. In the next section, we estimate the heating/cooling corresponding to the eddy diffusion coefficient used in calculations of the $[\mathrm{O}]$ seasonal variations. Note that the eddy diffusion coefficients should be increased by a factor of 2-3 to obtain [O] profiles similar to the profiles shown in Fig. 5 if the upward/downward motion corresponding to the adiabatic cooling/heating is included. 


\section{Heating and cooling by eddy turbulence}

There are different approaches and numerical models for estimating the heating/cooling rates induced by the gravity waves in MLT (Medvedev and Klaassen, 2003; Becker, 2004; Akmaev, 2007, 2009; Becker and McLandress, 2009). All models start from gravity waves and then calculate the heating/cooling corresponding to the different dynamic processes induced and driven by gravity waves. Some models estimate the eddy diffusion coefficient, as mentioned in the introduction. However, we start from the eddy diffusion coefficients and try to estimate the heating/cooling rates corresponding to them.

In this case, the heating/cooling rate of eddy turbulence is given by the formula (see Fritts and Luo, 1995)

$Q_{\mathrm{ed}}=\frac{\partial}{\partial z}\left[K_{\mathrm{ec}} C_{p} \rho\left(\frac{\partial T}{\partial z}+\frac{g}{C_{p}}\right)\right]+K_{\mathrm{ec}} \rho \frac{g}{T c}\left(\frac{\partial T}{\partial z}+\frac{g}{C_{p}}\right)$

where $K_{\mathrm{ec}}$ is the eddy heat conductivity, $\rho$ is the undisturbed gas density, $g$ is the gravitational acceleration, $T$ is the temperature, $C_{p}$ is the specific heat at constant pressure, and $c$ is a dimensionless constant commonly taken to be 0.8 (Lübken, 1997; Hocking, 1999). The first term on the right side of Eq. (3) is the heat flux divergence, and the second term is the turbulent energy dissipation rate initiated by the dynamic instability of gravity waves and the action of viscous and buoyancy forces. For example, the first term presents divergence of heat flux corresponding to the heat flux given by Becker (2004) for $P_{\text {reff }}=1$ and the heat flux given by formula (23) in Akmaev (2007). The second term is similar to the total wave energy disposition rate per unit mass, $\varepsilon=K \omega_{B}^{2}(1+P)$, given by Akmaev (2007) where $P$ may be considered a generalized Prandtl number and $\omega_{B}^{2}$ is the buoyancy frequency (Akmaev, 2007). There is great debate about the value of the turbulent Prandtl number. First of all, this problem is due to different assumptions about gravity wave energy transport and dissipation and localized or uniform induced turbulence. However, this problem is not within the scope of this paper. We restrict our calculations to only different values of $c$.

Around the mesopause, the temperature gradient is small and $\partial K_{\mathrm{ec}} / \partial z$ is small for the $K_{\mathrm{ec}}$ peak in the mesopause. In this case, Eq. (3) can be simplified to the formula

$Q_{\mathrm{ed}}=K_{\mathrm{ec}} g \frac{\partial \rho}{\partial z}+K_{\mathrm{ec}} \rho \frac{g^{2}}{C_{p} T c}$.

By dividing Eq. (4) by $\rho C_{\mathrm{v}}$ (where $C_{\mathrm{v}}$ is the specific heat at constant volume), multiplying by a time equal to one day, $\tau_{\mathrm{d}}$, and using the formulas $\rho=\rho_{0} \exp (-z / H)$ and $C_{p}=(1+$ $N / 2) \kappa / m$ where $H$ is the atmosphere scale, $N$ is a number of freedom degrees, $\kappa$ is the Boltzmann constant, and $m$ is the mean molecular mass, it is possible to transform Eq. (4) into

$Q_{\mathrm{ed}}=\frac{K_{\mathrm{ec}} g \tau_{\mathrm{d}}}{C_{\mathrm{v}} H}\left[\frac{1}{(1+N / 2) c}-1\right]$.

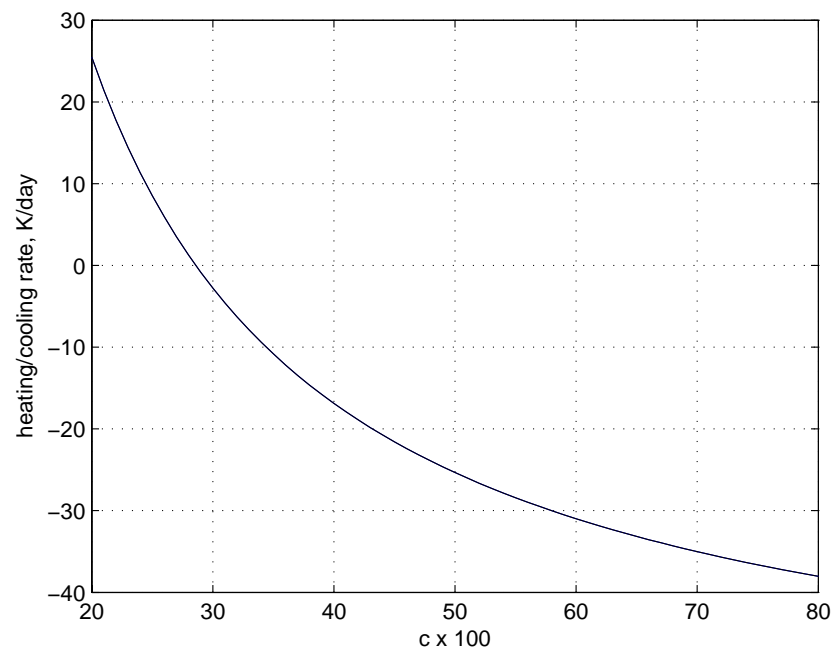

Fig. 6. Dependence of heating/cooling by eddy turbulence on the value of $c$, using Eq. (4) for $K_{\mathrm{ec}}=3 \times 10^{6} \mathrm{~cm}^{2} / \mathrm{s}$ and $H=6 \mathrm{~km}$.

As seen from Fig. 6, eddy turbulence can heat the mesopause for $c<0.286$ and cool it for $c>0.286$. The range of $c$ values can be estimated. The ratio of the turbulent energy dissipation rate due to the action of viscous and buoyancy forces to the transfer rate of kinetic energy from the mean motion to the fluctuating motion, $Q_{\text {eds }}=K_{\text {ed }} /(\partial u / \partial z)^{2}$, is determined by the ratio of the Richardson number, $R i=\omega_{B}^{2} /(\partial u / \partial z)^{2}$, to the turbulent Prandtl number, $P=K_{\mathrm{ed}} / K_{\mathrm{ec}}$. In the case of mean motion, $c$ can be estimated as being equal to $R i / P$. For the mean wind sheer of $20 \mathrm{~m} / \mathrm{s} / \mathrm{km}$ and $\omega_{B}^{2}=(3 / 5) \times$ $10^{-4} \mathrm{~s}^{-2}$, the $R i$ values are within the range of $0.75-1.25$ and the $c$ value is about 1 for $P \approx 1$. The $c$ value decreases with increasing $P$ and turbulent heating can dominate cooling. In any case, we can estimate the sensitivity of turbulent heating/cooling to the influence of wind shear and gravity waves.

Now we consider the heating/cooling caused by eddy turbulence in more detail. The height profile of the temperature given by the MSISE-90 model below the polar mesopause can be approximated by a linear dependence with the gradient $\partial T / \partial z=G=-5.4 \mathrm{~K} / \mathrm{km}$ in summer and $G=$ $-3.2 \mathrm{~K} / \mathrm{km}$ in winter solstice at latitudes $70^{\circ} \mathrm{S}$ and $70^{\circ} \mathrm{N}$, respectively. In this case, the density height distribution is given by the formula

$\rho=\rho_{0}\left(\frac{T_{0}}{T_{0}-G z}\right)^{1-m g / \kappa G}$,

and the heating/cooling rate given by Eq. (1) can be written as

$$
\begin{aligned}
Q_{\mathrm{ed}}= & K_{\mathrm{ec}} \frac{C_{p}}{C_{\mathrm{v}}} \tau_{\mathrm{d}}\left(\frac{g}{C_{p}}-G\right) \frac{G-m g / \kappa}{T_{0}-G z}+\frac{\partial K_{\mathrm{ec}}}{\partial z} \frac{C_{p}}{C_{\mathrm{V}}} \tau_{\mathrm{d}}\left(\frac{g}{C_{p}}-G\right) \\
& +K_{\mathrm{ec}} \frac{\tau_{\mathrm{d}} g}{C_{\mathrm{v}} c\left(T_{0}-G z\right)}\left(\frac{g}{C_{p}}-G\right) .
\end{aligned}
$$




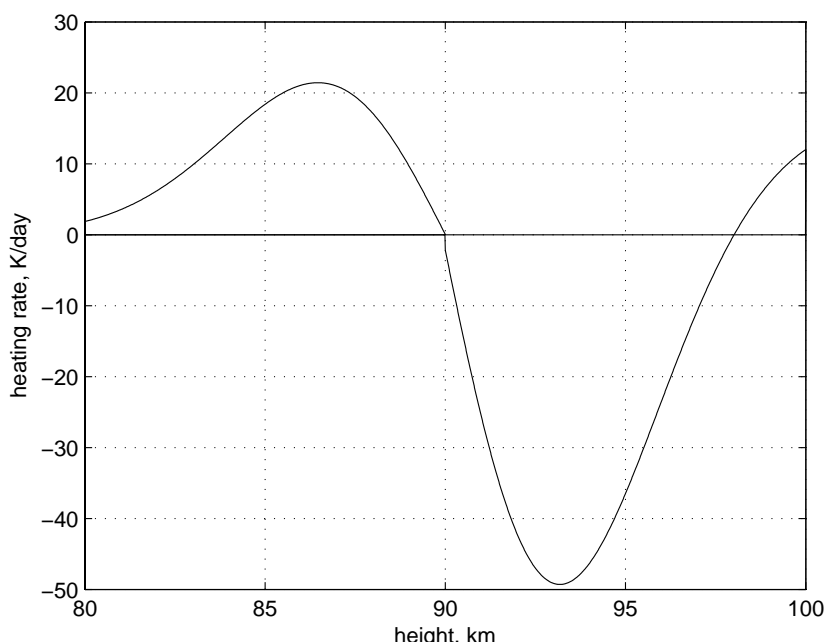

Fig. 7. The height profile heating/cooling rates calculated by Eq. (7) for summer conditions $\left(z_{m}=90 \mathrm{~km}, c=0.3\right.$, mesopause height $=90 \mathrm{~km}, G=-4 \mathrm{~K} / \mathrm{km}$ below $90 \mathrm{~km}$, and $G=5 \mathrm{~K} / \mathrm{km}$ above $90 \mathrm{~km})$

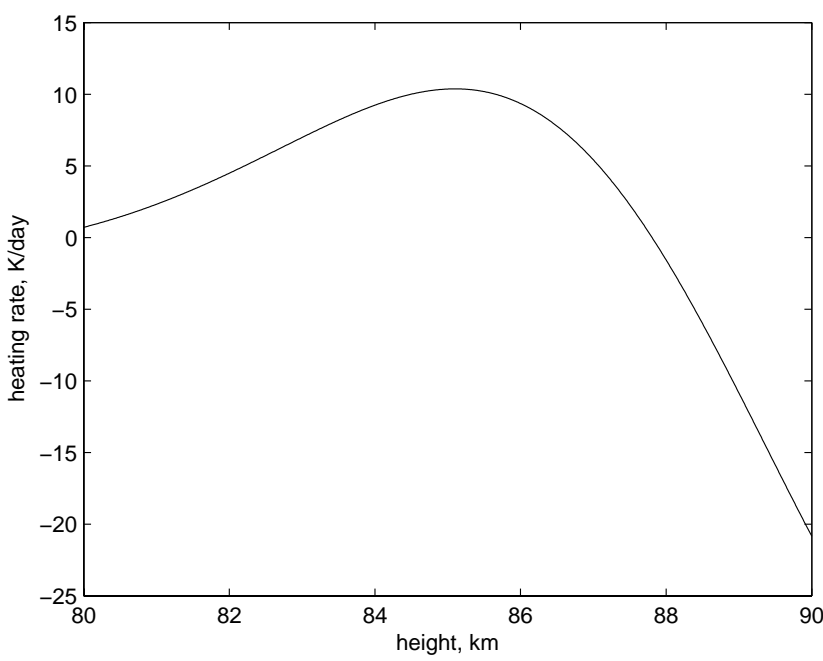

Fig. 8. The same as in Fig. 7 but below the $K_{\text {ec }}$ peak and with $c=0.8$.

The first term on the right side of Eq. (7) is negative because $\mathrm{mg} / \kappa$ is much larger than $G$. The second term is positive below the $K_{\text {ec }}$ peak and is negative above the $K_{\text {ec }}$ peak. The eddy diffusion coefficient inferred by Lübken (1997) from measurements of the turbulent energy dissipation rate in the summer polar mesosphere can be approximated by the formulas suggested by Shimazaki (1971):

$$
\begin{aligned}
& K_{\mathrm{ec}}=K_{\mathrm{ec}}^{0} \exp \left[S_{1}\left(z-z_{m}\right)\right]+\left(K_{\mathrm{ec}}^{m}-K_{\mathrm{ec}}^{0}\right) \exp \left[-S_{2}\left(z-z_{m}\right)^{2}\right] \\
& z \leq z_{m} \\
& K_{\mathrm{ec}}=K_{\mathrm{ec}}^{m} \exp \left[-S_{3}\left(z-z_{m}\right)^{2}\right] \quad z>z_{m}
\end{aligned}
$$

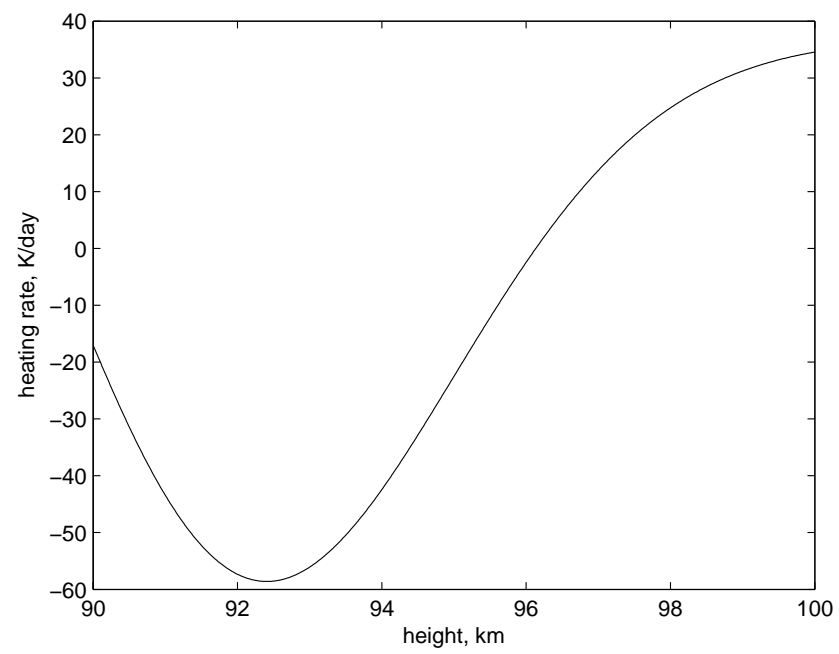

Fig. 9. The same as in Fig. 8 but above the $K_{\text {ed }}$ peak and with $c=0.8$.

where $K_{\mathrm{ec}}^{m}=1.8 \times 10^{6} \mathrm{~cm}^{2} / \mathrm{s}$ is the maximum of these coefficients, $z_{m}=90 \mathrm{~km}, S_{1}=0.05 \mathrm{~km}^{-1}, S_{2}=0.04 \mathrm{~km}^{-2}$, and $S_{3}=0.05 \mathrm{~km}^{-2}$. The same approximation is used in the [O] calculations. The height profiles of the heating/cooling rate calculated by Eq. (7) for $c=0.3$ and 0.8 are shown in Figs. 7, 8, and 9. Note that the summer polar mesopause is located at an altitude of $90 \mathrm{~km}$, according to the MSISE-90 model. Thus, the cooling rates calculated with the eddy diffusion coefficient inferred from measurements are found to be $-13.5 \mathrm{~K} /$ day and $-41.5 \mathrm{~K} /$ day for $c=0.3$ and $c=0.8$, respectively, at the mesopause. The strong change in the cooling rate with $c$ is explained by the strong increase in the dissipative term in Eq. (7) with the $c$ value decrease.

Using the same approach, we have calculated the heating/cooling rates in the polar winter mesosphere. The height profiles of these rates for $c=0.3$ and $c=0.8$ are shown in Figs. 10 and 11. Note that we increased the altitude of the $K_{\text {ec }}$ peak from $90 \mathrm{~km}$ (given by Lübken) to $92 \mathrm{~km}$ because, according to the MSISE-90 model, the altitude of the turbopause inferred from the vertical profiles of the $A r / N_{2}$ ratio is higher in winter than in summer. Comparing the cooling rates in the summer and winter mesopause, it is clear that the turbulent cooling rate in the winter mesosphere is much less than the cooling rate in the summer mesopause. This strong winter-summer asymmetry is well known (e.g., Becker, 2004).

As seen from the results discussed above, eddy turbulence cools the mesosphere at altitudes above and below the $K_{\mathrm{ec}}$ peak for $c>0.3$, and the maximum of this cooling rate is $-30 \mathrm{~K} /$ day $-50 \mathrm{~K} /$ day in summer and $-10 \mathrm{~K} /$ day in winter. Note that the maximum adiabatic cooling rate calculated by the SOCRATES model in the polar summer mesopause is $-16 \mathrm{~K} /$ day, meaning that eddy turbulence can provide the same or an even larger cooling rate than the hypothesized 


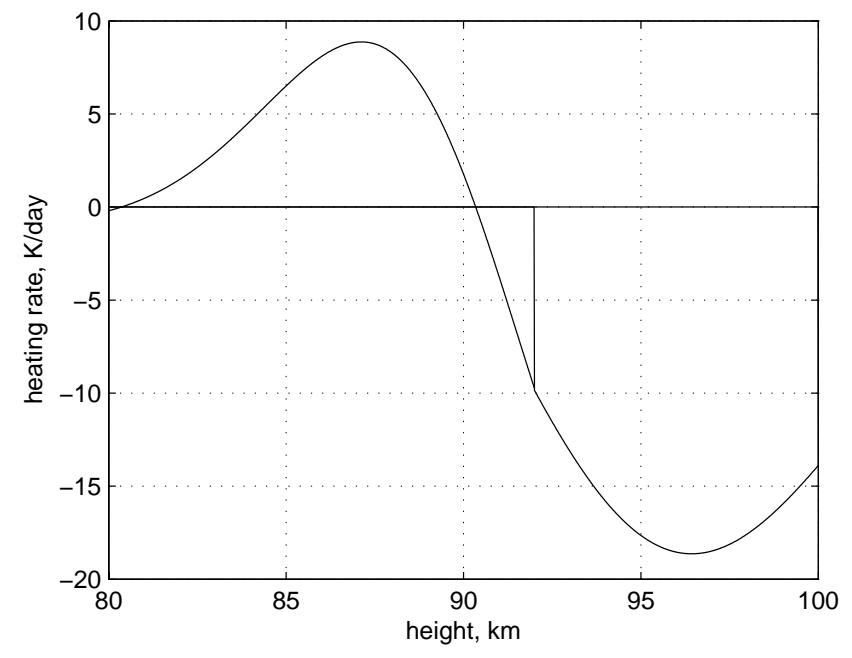

Fig. 10. The height profile of heating/cooling rates for winter conditions with $c=0.8$, a mesopause height of $100 \mathrm{~km}, G=3 \mathrm{~K} / \mathrm{km}$ below $92 \mathrm{~km}$, and $G=2 \mathrm{~K} / \mathrm{km}$ above $92 \mathrm{~km}$. The vertical line shows the $K_{\text {ed }}$ peak location.

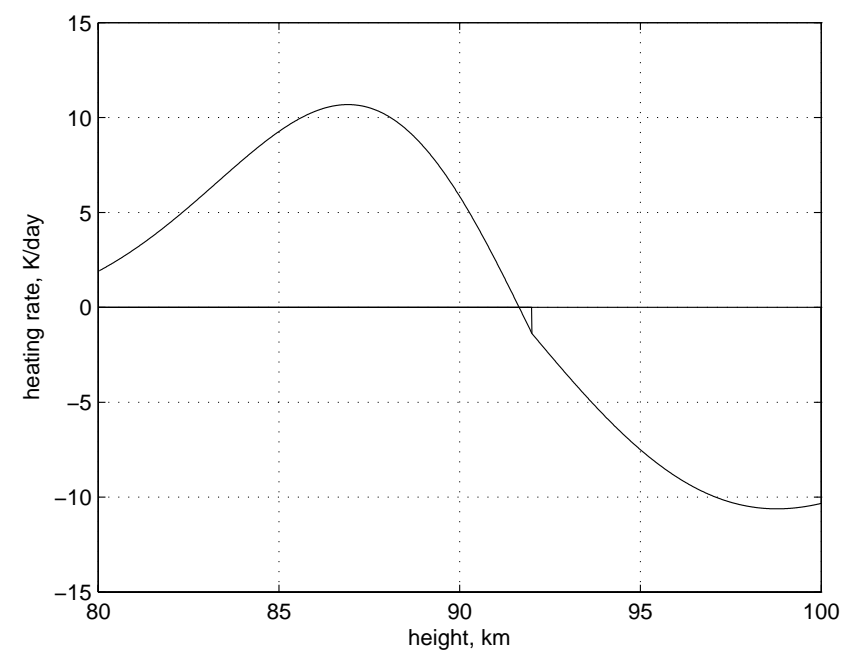

Fig. 11. The same as in Fig. 10 but with $c=0.3$.

adiabatic rate. The maximum of the turbulent heating rate does not exceed $+10 \mathrm{~K} /$ day, which is smaller than for adiabatic heating. Our results differ from the results of Fritts and Luo (1995) mentioned above because their model gives a $K_{\mathrm{ec}}$ peak at an altitude of $105 \mathrm{~km}$. However, this $K_{\text {ec }}$ peak location contradicts the MSISE-90 model because the turbopause altitude calculated using the $A r / N_{2}$ ratio is about $90 \mathrm{~km}$ in the polar summer MLT. In addition, radar observations by Ecklund and Balsley (1981) show that echoes in the summer polar mesosphere are caused by turbulence below $98 \mathrm{~km}$.

In the previous section, it was mentioned that the eddy diffusion coefficient should be increased by a factor of 2-3 if upward/downward motion occurs. In this case, the Prandtl number is larger than one and localized turbulent layers can take place.

\section{Conclusion}

Our results show that seasonal variations of the $\mathrm{O}$ density and the altitude of the [O] peak, calculated with upward/downward motion corresponding to adiabatic cooling/heating, are opposite to the observed seasonal variations given by the MSISE-90 model. Eddy turbulence with coefficients close to the values inferred from experimental data by Lübken (1997) can provide the observed seasonal variations of the $\mathrm{O}$ density and the altitude of the $[\mathrm{O}]$ peak. The heating/cooling by this eddy turbulence is comparable to or larger than adiabatic heating/cooling in the upper mesosphere. The strong impact of upward/downward motion and eddy turbulence on the [O] height distributions requires self-consistent modeling of the $\mathrm{O}$ density and temperature because of the important role of atomic oxygen in infrared cooling and chemical heating in the upper mesosphere. The eddy diffusion coefficients should be increased by a factor of 2-3 in order to obtain summer and winter [O] profiles close to the MSISE-90 data if upward/downward motion, corresponding to adiabatic cooling/heating, is taken into account.

Acknowledgements. Topical Editor C. Jacobi thanks E. Becker and another anonymous referee for their help in evaluating this paper.

\section{References}

Akmaev, R. A.: On the energetics of mean-flow interactions with thermally dissipating gravity waves, J. Geophys. Res., 112, D11125, doi:10.1029/2006JD007908, 2007.

Becker, E.: Direct heating rates associated with gravity wave saturation, J. Atmos. Solar-Terr. Phys., 66(6-9), 683-696, 2004.

Becker, E. and McLandress, C.: Consistent scale interaction of gravity waves in the Doppler spread parameterization, J. Atmos. Sci., 66, 1434-1449, 2009.

Banks, P. M. and Kockarts, G.: Aeronomy, Academic Press, New York, 1973.

Berger, U. and von Zahn, U.: The two-level structure of the mesopause: A model study, J. Geophys. Res., 104, 2208322093, 1999.

Brasseur, G. P. and Solomon, S.: Aeronomy of the Middle Atmosphere, 2nd ed., 452 pp., D. Reidel Pub. Co., Norwell, Mass., 1986.

Brasseur, G., Smith, A. K., Khosravi, R., Huang, T., Walters, S., Chabrillat, S., and Kockarts, G.: Natural and human-induced perturbations in the middle atmosphere: A short tutorial, in: Atmospheric Science Across the Stratopause, edited by: Siskind, D. E., Eckermann, S. D., and Summers, M. E., American Geophysical Union, Washington, D.C., 7-20, 2000.

Dunkerton, T. J.: On the mean meridional mass motions of the stratosphere and mesosphere, J. Atmos. Sci., 35, 2325-2333, 1978.

Ecklund, W. L. and Balsley, B. B.: Long-term observations of the arctic mesosphere with the MST radar at Poker Flat, Alaska, J. Geophys. Res., 86, 7775-7780, 1981.

Fomichev, V. I., Ward, W. E, Beagley, S. R., McLandress, C., McConnell, J. C., McFarlane, N. A., and Shepherd, T. G.: Extended 
Canadian Middle Atmosphere Model: Zonal-mean climatology and physical parameterization, J. Geophys. Res., 107(D10), 4087, doi:10.1029/2001JD000479, 2002.

Fritts, D. C. and Luo, Z.: Dynamical and radiative forcing of the summer mesopause circulation and thermal structure 1 . Mean solstice conditions, J. Geophys. Res., 100, 3119-3128, 1995.

Fukao, S., Yamanaka, M., Ao, N., Hocking, W., Sato, T., Yamamoto, M., Nakamura, T., Tsuda, T., and Kato, S.: Seasonal variability of vertical eddy diffusivity in the middle atmosphere 1. Three-year observations by the middle and upper atmosphere radar, J. Geophys. Res., 99(D9), 18973-18987, 1994.

Gardner, C. S. and Yang, W.: Measurements of the dynamical cooling associated with vertical transport of heat by dissipating gravity waves in the mesopause region at the Starfire Optical Range, New Mexico, J. Geophys. Res., 103, 16909-16926, 1998.

Hedin, A. E.: Extension of the MSIS thermospheric model into the lower and middle atmosphere, J. Geophys. Res., 96, 1159-1172, 1991.

Hill, R. J., Gibson-Wilde, D. E., Werne, J. A., and Fritts, D. C.: Turbulence-induced fluctuations in ionization and application to PMSE, Earth Planets Space, 51, 499-513, 1999.

Hines, C. O.: Doppler-spread parameterization of gravity wave momentum deposition in the middle atmosphere. Part 1: Basic formulation, J. Atmos. Solar-Terr. Phys., 59, 371-386, 1997.

Hocking, W. K.: The dynamical parameters of turbulence theory as they apply to middle atmospheric studies, Earth Planets Space, 51, 525-541, 1999.
Larsen, M. F.: Winds and shears in the mesosphere and lower thermosphere: Results from four decades of chemical release wind measurements, J. Geophys. Res., 107, 1215, doi:10.1029/2001JA000218, 2002.

Lübken, F.-J.: Seasonal variations of turbulent energy dissipation rates at high altitudes as determined by in situ measurements of neutral density fluctuations, J. Geophys. Res., 102, 1344113456, 1997.

Medvedev, A. S. and Klaassen, G. P.: Thermal effect of saturating gravity waves in the atmosphere, J. Geophys. Res., 108, 4040, doi:10.1029/2002JD002504, 2003.

Shimazaki, T.: Effective eddy diffusion coefficient and atmospheric composition in the lower thermosphere, J. Atmos. Terr. Phys., 33, 1383-1401, 1971.

Smith, A. K.: Physics and chemistry of the mesopause region, J. Atmos. Solar-Terr. Phys., 66, 839-857, 2004.

Vlasov, M. N. and Davydov, V. E.: Theoretical description of the main neutral constituents in the earth's upper atmosphere, J. Atmos. Terr. Phys., 44, 641-647, 1982.

Vlasov, M. N. and Davydov, V. E.: The effect of vertical transfer on the composition of the thermosphere during geomagnetic disturbances, Kosmicheskie Issled, 21, 725-730, 1983.

Vlasov, M. N. and Davydov, V. E.: Splitting of atomic oxygen height profiles by eddy diffusion, J. Atmos. Terr. Phys., 55, 1361-1363, 1993. 